\title{
A Product Development Approach to Teaching Introductory Engineering Design
}

\author{
L. M. Lye \\ Memorial Universityof Newfoundland \\ llye@engr.mun.ca
}

\author{
A. D. Fisher \\ Memorial University of Newfoundland \\ adfisher@engr.mun.ca
}

\begin{abstract}
This paper describes a new approach to teaching first year design at Memorial University. Students are introduced to engineering design using the product realization process (PRP) as a platform. The course integrates the business, engineering design, and prototyping functions of the PRP. The just-in-time structured delivery of background tools and theory complement the relatively unstructured nature of the design problems. Lab exercises are used to intoduce the basic practicalities of mechanical, electrical and electronic design. Projects are completed in teams with emphasis placed on teamwork, project management and communication skills. Student enthusiasm has been very high and this aides significantly in the learning process.
\end{abstract}

\section{Introduction}

Engineering programs across Canada typically have an introductory course (first year) in engineering design where the students are introduced to the problem solving process. The course normally includes problem definition and specification, generation of alternative solutions, decision analysis, project planning, communication, teamwork, and presentation skills. This is often a common course taken by all engineering students regardless of discipline. Students are expected to work in teams on projects that are either self-generated or assigned by the instructor.

This approach was also used at the Faculty of Engineering and Applied Science at Memorial University until the end of 2003. There was general dissatisfaction with the approach because the content of the course tended to be highly dependent on the instructor assigned and students tended to be left to complete their projects unguided. This may be related to the difficulties there are in recruited experienced design professionals into faculty positions. Certainly the nature of the course is one that calls for a generalist and not a specialist.

In this paper, a new approach in teaching the first year design course at Memorial University will be described. This new approach introduces students to engineering design using the product realization process as a focus as opposed to looking at the narrower design process. While this approach of teaching engineering design is new at Memorial University, the approach is modelled after a similar course taught at the graduate level to engineering, business, and industrial design students at the Massachusetts Institute of Technology (MIT), Sloan School of Business, and Rhode Island School of Design, respectively. One could argue that the background of the the MIT students is significantly different than our first year engineering students, but it should be noted that the course is also quite similar to the four-week Shad Valley program offered each year to top high school students at various universities across Canada.

The course integrates the business, engineering design, and prototyping functions of a firm in creating a new product. It is intended to provide students with the following benefits: competence with a set of tools and methods for product design and development; confidence in their own abilities to tackle open-ended design problems; awareness of the cross-disciplinary nature of product development (e.g. marketing, finance, industrial design, business planning, prototyping, manufacturing, etc); structured practice in project management; and familiarity with the fundamental nature of engineering design. Student feedback has noted that all of these benefits accrue in a fast-paced, engaging and "fun" process.

This paper is generally descriptive in nature and provides an outline of the course structure and delivery technique. Section 2 covers the structure of the course and details the topics to be covered and Section 3 
outlines the project guidelines. This is followed in Section 4 by a detailed description of the individual and team assignments to be handed in each week. Section 5 provides a discussion of the lessons learned from the new course, student's feedback about the course, and some conclusions. The final section provides a list of some of the reference material used for the course.

\section{Structure}

The design course consists of three interconnected parts; lectures on various topics pertaining to the product realization process, practical lab exercises including occupational health and safety $(\mathrm{OH} \& \mathrm{~S})$ and a team design project. Each of these aspects will be described in further detail in the following sections.

\subsection{Lectures}

The purpose of the lectures is to provide the tools, techniques, and guidance for the design and development process. This material, which spans the breadth of the product development process (PDP), was recently well documented by Salustri and Proulx [1] as part of the Canadian Design Engineering Network (CDEN) project. The topics are designed to pace the teams' product design and development phases (i.e. just-in-time delievery). The lectures are normally between one and one and one half hour long, but given in a three hour time slot, leaving plenty of time for discussion and coaching. Lecture topics include:

- Design processes and organization: a discussion of science versus engineering, the product development process versus design, the challenges and rewards of product design and development, and basic project management

- Mission statement and identifying customer needs: mission statements and their uses, steps involved in identifying customer needs, guidelines for writing needs statements, and exercises in needs translation.

- Product specifications: what are specifications, steps in establishing target specifications, final specifications, steps involved in final specifications, and exercises in establishing specifications.

- Concept generation: activity of concept generation, steps in concept generation, common dysfunctions during concept generation, methods of concept generation and exercises.

- Concept selection and testing: overview of methodology for concept selection, concept screening and scoring, decision analysis, steps involved in concept testing, concept communication, measuring customer response, judging potential sales, examples and exercises.

- Intellectual Property (IP): what is IP, why is IP important, types of IP, IP relevant to product design, overview of patents, steps in preparing a disclosure, common mistakes with regard to patenting an invention, IP resources, costs involved in obtaining a patent, and conducting patent searches.

- Basics of business planning: what is a business plan, uses of a business plan, components of a business plan, sample business plans, and resources for writing business plans.

- Design for manufacturing and assembly (DFM and DFA): what are DFM and DFA, why are DFM and DFA important, elements of manufacturing costs, DFM and DFA guidelines, and exercises.

- Industrial design (ID) and prototyping: what is ID, critical goals for ID, how important is ID to a product, ID resources, examples of award winning designs, what is a prototype, types of prototypes, uses of prototypes, physical versus analytical prototypes, prototyping strategy, rapid prototyping methods, virtual prototypes and traditional methods, and steps in planning for prototypes.

- Design for the environment (DFE): why design for the environment, stages of a product life cycle, material and energy flow over a product life cycle, environmental objectives, CERES principles, global and local issues, climate change, DFE guidelines, product structure guidelines, material selection guidelines, labelling and finishing guidelines, fastening guidelines, and useful resources.

Assignments are due weekly to provide the overall structure to the process. In addition to the lectures, students are asked to read the various articles provided in their handbook that are relevant to the discussion topics. This material include articles from Inventor's Digest and other magazines. The lectures are typically given by the course instructor, although "experts" are brought in wherever possible (in 2005 this included IP, business planning and DFE) These individuals were also available for consultations throughout the duration of the course. Lecture notes are provided in full on the course web site in addition to links to many useful web resources.

\subsection{Practical Lab Exercises}

One of realities of our modern society is that many of the opportunities for practical experiences are disappearing. Our own experience suggests that each year there are fewer and fewer first year students who have been exposed to maintenance, construction, welding, electrical troubleshooting or other similar 
activities. In fact, we have chosen to assume that the vast majority of engineering students are almost completely unfamiliar with handtools, how machinery works, and how things are made. The challenge for any early design program is to get students to do something they are completely unfamiliar with in order to gain the experience necessary to be able to tackle this type of problem. This challenge was well documented many years ago by Schon [2].

In order to mitigate this particular challenge to the extent possible, the course incorporates a practical lab component. These exercises are not tailored to support any specific type of product development, but are designed to cover a broad range of practical applications. It is not clear that the exact nature of the exercises even matters in terms of the development of an inquisitive nature and an understanding that every manmade artifact we contact is providing us with a wealth of design information.

The current suite of lab exercises includes the disassembly and assembly of a lawnmower engine (including a functional test), a lathe manufacturing exercise, a milling manufacturing exercise, electronic circuit soldering and testing, electrical wiring, welding and pipe soldering. While it is only a side-effect, it is worth commenting on the visible excitement when these students get their lawn mower running again or build a small loop of copper pipe and take it home.

The students have a very minimal documentation requirement for these exercises and no formal mark is awarded. The exercises are simply shown as a requirement for successful completion of the course. Despite this lack of a grade "reward", the labs are incredibly well attended and we are continually asked to provide more of these opportunities. When combined with the design project, they provide a good example of how engineering differs from most of their educational experiences up to this point.

Since this is expected to be the students' first exposure to this type of practical application, they are given an introduction to Occupational Health and Safety (OH\&S) as part of this component of the course. The OH\&S training includes lab safety, WHMIS, transportation of dangerous goods, fire safety, work standards and relavent labour laws. The training is very focused and concise and is evaluated with a formal test which is given in lieu of a mid-term exam. This test is marked on a pass/fail basis and does not effect the student's grade for the course, but is a requirement for graduation.

\subsection{The Design Project}

The challenge for the students in the project portion of this course is to design a new product and to produce a prototype. The goal of this exercise is to facilitate the learning of principles and methods of product development in a realistic context. Most product development professionals work under tremendous time pressure and do not have an opportunity to reflect on the development process. These professionals often forgo the use of formal methods and rely on their experience as discussed in detail by Green and Bonollo [3]. Students on the other hand can benefit from the structure of formal methods to ensure a reasonable result is achieved in the absence of broader experience. In this course, the project stress levels are low enough that there is time to experiment and learn. Project ideas come from students in the class. The guidelines for "reasonable" projects are given in the next Section 3.

This course takes approximately six hours per week of the student's time not including the practical lab exercises. It is expected that each student will prepare for and attend all of the class sessions and will contribute regularly and substantially to their team project. The workload for the course is fairly manageable, with increased project effort at the end of the semester offset by lighter preparation for class. Full group collaboration is strongly encouraged because of the clear importance of teamwork and having a broad representation of viewpoints involved in product development.

\subsection{Grading}

Student performance in the course is measured on both individual and team effort. Individual and team expectations are discussed in further detail in the next section. The grading scheme is as follows: $5 \%$ for the individual project presentation, $10 \%$ based on the the individual project proposal, 50\% for the team's work on project-related assignments, $20 \%$ based on the content and quality of the team's final project presentation, and $15 \%$ based on a final exam.

The individual's contribution to the team is based on the quality of the logbook kept and the assessment of the team members. For example, if the majority of the team members felt that a student contributed only $20 \%$ to the team effort, that student would only get $20 \%$ of the team's mark. Detailed guidelines on how to keep a log book were given in the course manual and the course website.

\subsection{Project Teams}

In the third week of the course, the project teams are formed after each student had presented their 
individual design opportunity idea to the class. These are presented as needs or problems, not as products. Each student then lists the projects they would like to work on in a preference form. Students choosing the same projects would be put in the same team. Teams consist of about six to nine students depending on the number of students in the class. Once they were assigned to a project team, it was expected that they stay with the team for the entire term. During the winter term of 2004, there were 24 teams from 170 students. This year (2005), there were 25 teams from about 200 students. Each team would normally work on a different project. If a particular project idea is very attractive it is possible that more than one team would work on the same idea. In those cases, the teams would be competing against each other - like two competing companies trying to come up with similar products.

\subsection{Project Materials and Expenses}

A student's out-of-pocket expenses related to the course projects would normally be less than $\$ 50$. Each team's budget should not be more than $\$ 400$. Since there were no expensive texts to buy, a $\$ 50$ investment is quite reasonable. The $\$ 50$ is considered an investment in a company. The expenses for the team include the purchase of materials for making the various prototypes, buying of services such as hiring a machinist for making a part, web design, equipment rental, transportation, welding and other forms of fabrication expenses, etc.

\subsection{Intellectual Property Rights}

The student teams will be able to retain the rights to any inventions they develop in this course. If a team should decide to pursue a patent, they may do this on their own. Alternatively, the team can choose to share their invention with the university which may be interested in patenting it, in exchange for a portion of any licensing royalties. The teams were advised to spend some time during an early meeting to decide in advance on how to distribute any economic rewards arising from the intellectual property they may create. The project assignments and individual logbooks will then serve as a dated record of the evolution of their ideas. Although intellectual property is a real issue for a product development firm, given the costs and time required to pursue a patent, this is normally out of reach for students in the course. However, students were encouraged to follow the proper process just in case.

\section{Guidelines for Projects}

While special cases will be considered, students were strongly encouraged to choose a project satisfying all of the following constraints:

- There should be a demonstrable market for the product. A good way to verify a market need is to identify existing products that attempt to meet a need. The product need not be a variant of an existing product, but the market need addressed by the product should be clearly evident. The product does not need to have a tremendous economic potential, but should at least be an attractive opportunity for an established firm with related products and/or skills.

- Products to be developed in this course should be engineered, discrete, and physical. Hence products such as gasoline, nylon, paper, services, or software would not meet the guidelines. While many of the ideas in the course apply to services and software products (for example, customer needs), many do not (for example, prototyping).

- The product should have a high likelihood of containing fewer than 10 parts. Although it is difficult to anticipate the design details, it is easy to anticipate that an electric drill will have more than 10 parts and that a door stop or bottle opener will have fewer than 10.

- The product should be able to be prototyped for less than \$200. Students are told not to be too ambitious as they are limited by time, money, and technical know-how at present.

- The product should require no basic technological breakthroughs. There is no time to deal with large technological uncertainties.

- The product should have more than five potential lead users and more than 10 would be ideal.

Most successful projects tend to have at least one team member with strong personal interest in the target market (i.e. a champion for the product). Students were also advised to do some research to identify competitive products and solutions. Of the approximately 200 product ideas put forth each year, the following list shows some of the challenges which were picked during the last two offerings of the course:

- heated outdoor mat, lawn mower grass extractor, tennis ball tester, snowmobile flotation, shingle roof lift, drum deadener, ice-roller skates combo, back pack johnny, snowmobile locator, water weights, skidoo ski-saver, non-fogging paintball mask, TV remote finder, hose rewinder, toilet paper reloader, LED lantern, automatic auto visor, peg winder, safety grip crutch, heated steering wheel cover, automatic door threshold sealer, more effective fridge shelving, 
motion-charged LED flashlight, backpack/purse internal lighting.

As can be seen, the products proposed and developed were quite varied. Some products required more technical know-how than others, but in general the technical knowledge required was all within the capabilities of the students. Any specialised knowledge required was learned while working on the project. Students were advised to consult widely within and outside of the university. In general all the technical staff, vendors, and faculty members were very helpful and supportive of their efforts.

\section{Individual and Team Assignments}

As mentioned earlier, there were individual assignments and team assignments. These assignments were intended to pace the development process for the student products. Since there no slack in the schedule, all assignments must be completed on or before the scheduled due date in order to maintain the project schedule. Details of the instructions given to the students for the individual and team assignments are given below.

\subsection{Individual Assignments}

Part 1: Proposal Handout - Due Week 3

Each student prepares a project proposal in a format that fits on one $8.5 \times 11$ page (one side only). Proposals include a brief, descriptive project title (2-6 words), student contact information, and a description of the product opportunity you have identified. The description may include any of the shortcomings of existing competitive products, as well as a definition of the target market and its size. Students are asked not present any of their own product ideas at this point.

Part 2: Proposal Presentation - Due Week 3

Students are asked to prepare a 60-second presentation to be delivered in class. These presetations are to include: an self-introduction, a verbal or visual demonstration of the product opportunity you have described in your proposal, and an indication of any special skills or assets (e.g. marketing expertise, access to a shop, a car, electronics wizardry, woodworking tools, etc.). Students must clearly explain the richness of the market opportunity in order to attract other students to their project. Showing one or two overhead slides is recommended.

Part 3: Project Preferences - Due Week 3

Project preferences are submitted after students see the presentations of their colleagues. They are asked to list the ten projects they would like to work on, in order of preference.

\section{2: Team Assignments/Projects: Guidelines}

\section{Assignment 1: Mission Statement and Customer Needs List - Due Week 4}

Each team must submit a report showing the team's processes for getting organized and for identifying customer needs. The report must include a mission statement and name for the project team, as well as a list of task assignments (who's CEO, who's in-charge of finance, research, drafting, etc.). The report must also include an organized list of customer needs for the product and should include a copy of the original project proposal.

\section{Assignment 2: Concept Sketches and Target Specifications - Due Week 5}

This report must describe the steps of the concept generation and target specification processes, with comment on the process and the results. It must include sketches and bullet-point descriptions of 10 to 20 alternative concepts for meeting the customer need. Each sketch must clearly indicate which of the important customer needs it addresses and which it does not. For a few (perhaps 3 or 4 ) critical customer needs, the students are asked to prepare a list of the target specifications and provide documentation to support these decisions.

\section{Assignment 3: Preliminary Concept Selection - Due Week 6}

This report includes sketches of the two or three concepts that are thought to be most promising. The concept selection matrix (screening, scoring, CIA) that was used to make these choices must be clearly shown. The report must include a simple description or sketch of each of the concept alternatives considered. There should be a list of the key uncertainties or questions still needed to be addressed to determine the viability of the product. Each uncertainty should be accompanied by an associated plan of action (such as analysis, mock ups, interviews, experiments, etc.). Finally the report must include a description of the team's process, with comment on the process and the results.

Assignment 4: Review: Final Concept, Model, and Schedule - Due Week 8

Teams must prepare a 10-minute (maximum) presentation of the final (single) selected product concept. The presentation is to include a review of the team mission statement, customer needs, selected concept, and the key target specifications. As part of the presentation, the team must demonstrate some 
form of proof-of-concept prototype model. Groups are required to hand in a one-page description and sketch of the selected concept.

In addition, the team has to prepare a schedule in Gantt-chart form showing the work completed to date as well as a plan for the work to be completed over the remainder of the term. The plan should include at least the following activities: detail design, materials and components selection, vendor selection, procurement of materials and components, testing, and completion of assignments. Finally, the report must include a description of the team's process with comments on the process and the results.

Assignment 5: Drawings, Plans, and Revised Schedule - Due Week 9

The teams must prepare an assembly drawing of the alpha prototype they intend to build. The assembly drawing must show all the parts in their assembled positions. In addition, the groups must prepare dimensioned sketches of each part of the planned prototype. The report must include documentation showing how critical dimensions were arrived at. It must also include a bill of materials indicating whether the prototype parts will be purchased or fabricated, and a description of the assembly process. The report must also indicate the material and fabrication process selected for each prototype part. Photocopies of the vendor specification sheets for the purchased materials and components must be included.

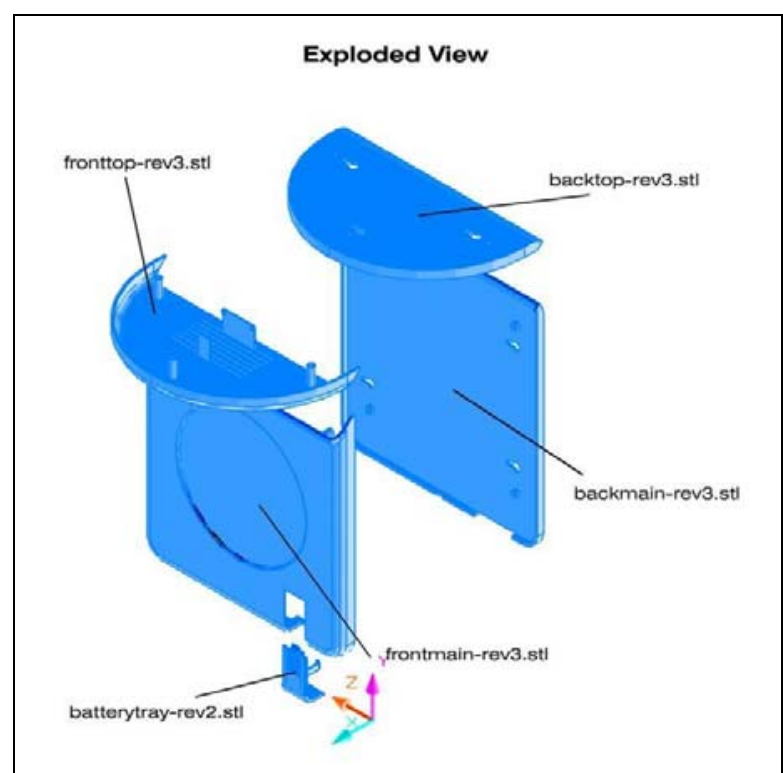

Figure 1. Sample prototyping part illustration

The team must generate a drawing or sketch of the production version of the product. The report must describe the differences between the prototype to be built and the production product. It should also briefly explain how the production product would be manufactured. In addition the report must summarize the important decisions made since the previous assignment and describe any prototyping plans. See Figure 1. (Price quotes and prepared orders should be ready for any parts to be fabricated or purchased.)

The team must revise the schedule of their project work for the remaining weeks. This revised plan should include the planned design work, vendor interactions, prototyping, testing, redesign, photography, and preparation of the presentation. As always, the report concludes with a description of the team's process with comments on the process and the results.

\section{Assignment 6 : Patent Review - Due Week 10}

Each team must prepare background information for a patent lawyer/agent to review. To do this, they need to explain the exact nature of any invention(s) within their product that may be patentable. This must include a statement of the invention's novelty, utility, and non-obviousness. The report mus provide references to any U.S. and Canadian patents that are related to the team's invention. (It is not necessary for a product to be patentable, but this also needs to be dicussed in the report.)

\section{Assignment 7: Alpha Prototype - Due Week 11}

Student teams should be testing their product prototypes by this time. Each team is required to demonstrate their prototype hardware to the instructional faculty during this week. Based on this interaction, the faculty will provide the team with feedback and any necessary coaching to help the group be as successful as possible.

\section{Assignment 8: Final Presentation and Demonstration - Due Week 12}

Each team must prepare a 15-minute (maximum) presentation describing and demonstrating their product. The presentation is intended to concentrate on the product itself, although the teams may wish to emphasize any particularly impressive portions of their development process. Expections are for an effective presentation which includes colour pictures or graphics or video presentation along with a live display of the hardware. Each group must also create and demonstrate a web page designed to promote their product. A copy of these presentations (and files for the web page) must be submitted upon completion of the presentation. Several high-quality digital photos of the prototype hardware (150dpi JPEG files preferred) are also required. Ideally these should be photos of the product in use. 


\subsection{Judging the Final Presentation}

The students are advised that the final presentation should be of the quality they would make to convince a top management group to purchase the rights to their product or to fund its final development and launch. They are also informed that a panel of experts will observe their presentations and evaluate their products and that they should be prepared to answer questions about all aspects of their project. Four external judges are used, although they very from year to year. In the past they have included: the university's intellectual property officer, a manufacturing plant manager, an office secretary (representing the customers), a mechanical product designer, a business development officer and an electrical engineer/management consultant.

The dean of the Faculty of Engineering was also kind enough to provide $\$ 500$ as prize money ( $1{ }^{\text {st }}$ prize of $\$ 250,2^{\text {nd }}$ prize of $\$ 150$, and $3^{\text {rd }}$ prize of $\$ 100$ ) for the top three project teams. It is hoped that in future some or all of the prize money would come from external sponsors.

The Winter 2005 presentations were recorded and put on a DVD. These DVD's were then offered to the students for $\$ 10$ and the proceeds were contributed to the Red Cross. To date, over 70 of these DVD's have been purchased. This is pretty clear indication of the enthusiasm that these students had for this course.

\section{Discussion and Conclusion}

In general, students' feedback on the new approach for the introductory design course was overwhelmingly positive. Students loved the realistic, fun, and hands-on approach of the course. They also liked the fact that expectations for the assignments were made very clear in a course handbook. Given the "scripting" of the course they found that the guidance they received from the instructors through the lectures and regular consultations was exactly sychronized with the expectations placed on them. For some students the most engaging part of the course was that they got the chance to be creative and to design and make something tangible. Many students also learned much about and from their fellow students and about working in teams. They come to realise that many of their classmates are very creative individuals and possessed a variety of useful technical and nontechnical skills.

A majority of the students were also pleased that they got to learn many useful skills that they had not fully associated with design and product development.
These include business planning and budgeting their own limited funds for various phases of their project; researching for information on patents, products, and pricing; searching for manufacturers and suppliers of raw and processed materials; and communicating with a variety of people (e.g. potential customers, suppliers, retailers, a variety of experts, etc). Many teams also made full use of the opportunity to use the university's rapid prototyping facility and/or the $\mathrm{CNC}$ machining capability to build their prototypes.

From the instructor's point of view, expectations were set very high. In general students rose to this challenge and in many cases delivered more than was imagined possible at this first year level. The workload for the students was heavy but not in terms of studying. Much time was invested in making their product idea work. This type of work provides the students with a refreshing change from their many academic challenges in other courses. It was gratifying to see the camaraderie built up over the term and creativity of the students.

The winning team really wowed the audience and judges with their colour brochures, a humorous video skit of the product in use, a well-designed website, and a great, professional looking presentation. The prize money did provide additional motivation to all the teams, although this wasn't officially annouced until later in the term. It also allowed the winning teams to recover some or all the money they had invested in their project, and, of course, bragging rights.

The only aspect of the course that was not very popular was the fact that there was a final examination. Many students felt that there was no need for it since the work load for the course was heavy enough. However, after the final examination was taken, most students changed their minds about the need for the final examination and realised that that is the only way the concepts and principles of the product realization process can can be tested and acts as a final reinforcement of the concepts the students are expected to take away with them.

In addition, the final exam was used as a means for assessing the contribution of each team member to the project by asking each student to describe their project in detail, their role in the team, the role of each team member, and their assessment of the contribution made by each team member. If this highlighted any concerns, the logbooks were used to cooberate the relative contributions.

In conclusion, the new approach to teaching the introductory design course at Memorial was an unqualified success. The open-ended, fun, creative, and realistic aspects of the course will equip the students with lifelong skills that will be of great 
benefit in their future careers and hopefully encourage many of them to follow on with further design work.

A final note is that the Winter 2006 offering will be the last time this course can be offered in this format do to a major restructuring of the engineering program at Memorial. It is hoped that the best elements of this current approach can be captured and translated into the new structure to maintain the momentum for design.

\section{References}

[1.] F.A. Salustri and D. Proulx, "Overview of Product Development Processes", v1.00, http://deed.ryerson.ca/x/pub/Dcl/pdpo-100.pdf, 2004

[2.] D.A. Schon, Educating the Reflective Practitioner, Jossey-Bass Publishers, San Franscisco, 1987.

[3.] L.N. Green and E. Bonollo, "The Importance of Design Methods to Student Industrial Designers", Global J. of Engineering Education, vol. 8, no. 2, pp. 175-182, Australia, 2004.

[4.] K.R. Allen, Bringing New Technology to Market, Prentice Hall, New Jersey, USA, 2003.

[5.] J. Cagan and C.M. Vogel, Creating Breakthrough Products, Prentice Hall PTR, New Jersey, USA, 2002.

[6.] T.T. Gordon and A.S. Cookfair, Patent Fundamentals for Scientists and Engineers, $2^{\text {nd }}$ Edition, CRC Press LLC, Florida, USA, 2000.

[7.] Inventors' Digest (various issues): JMH Publishing Company.

[8.] J.R. Lindbeck, Product Design and Manufacture, Prentice Hall, New Jersey, USA, 1995

[9.] D.A. Norman, The Design of Everyday Things, Paper Back Edition, Basic Books, USA, 2002.

[10.] K. Otto and K. Wood, K., Product Design: Techniques in Reverse Engineering and New Product Development, Prentice Hall, New Jersey, USA, 2001.

[11.] K.T. Ulrich and S.D. Eppinger, Product Design and Development, $3^{\text {rd }}$ Ed., McGraw Hill, USA, 2004

[12.] G. Voland, Engineering by Design, $2^{\text {nd }}$ Ed., Prentice Hall, New Jersey, USA, 2004. 